\title{
Noncoding RNAs in multiple sclerosis
}

\author{
Xuan Yang ${ }^{1,2+}$, Yuzhang $\mathrm{Wu}^{3+}$, Bei Zhang ${ }^{1 *}$ and Bing $\mathrm{Ni}^{2^{*}}$ (D)
}

\begin{abstract}
Multiple sclerosis (MS), a chronic inflammatory demyelinating disease of the central nervous system, is characterized by axonal degeneration and gliosis. Although the causes of MS remain unknown, gene dysregulation in the central nervous system has been associated with the disease pathogenesis. As such, the various regulators of gene expression may be contributing factors. The noncoding (nc) RNAs have piqued the interest of MS researchers due to their known functions in human physiology and various pathological processes, despite being generally characterized as transcripts without apparent protein-coding capacity. Accumulating evidence has indicated that ncRNAs participate in the regulation of MS by acting as epigenetic factors, especially the long (I) ncRNAs and the micro (mi) RNAs, and they are now recognized as key regulatory molecules in MS. In this review, we summarize the most current studies on the contribution of ncRNAs in MS pathogenic processes and discuss their potential applications in the diagnosis and treatment of MS.
\end{abstract}

Keywords: ncRNAs, IncRNAs, miRNAs, circRNAs, Multiple sclerosis

\section{Background}

Next-generation sequencing of the human genome revealed the unexpected finding that $<2 \%$ of the total genome sequence encodes proteins [1], yet up to $90 \%$ of eukaryotic genomes are transcribed, generating noncoding (nc) RNAs that lack an open reading frame and have no protein-coding potential $[2,3]$. The ncRNAs are classified according to transcript size; those with length of $<200 \mathrm{nu}-$ cleotides (nt) are considered small or short ncRNAs-represented by the micro (mi) RNAs that are dominant among small RNAs in eukaryotic cells, the small interfering (si) RNAs and the Piwi-interacting (pi) RNAs ncRNAs - and those with length of $>200$ nt are considered long (l) ncRNAs, featuring highly diverse structures and functions [4-6]. Upon their discovery, the ncRNAs were largely dismissed as "transcriptional noise," but studies have since suggested that this proverbial "dark matter" of the genome may play a major biological role in the development and metabolism of cells and in the pathogenesis of many diseases $[7,8]$.

\footnotetext{
* Correspondence: 914054186@qq.com; nibingxi@126.com

${ }^{+}$Xuan Yang and Yuzhang Wu contributed equally to this work.

${ }^{1}$ Department of Immunology, Medical College of Qingdao University, 308

Ningxia Road, Shinan District, Qingdao 266003, China

${ }^{2}$ Department of Pathophysiology, Third Military Medical University, 30

Gaotanyan St., Shapingba District, Chongqing 400038, China

Full list of author information is available at the end of the article
}

Multiple sclerosis (MS) is a chronic inflammatory demyelinating disease of the central nervous system (CNS) and characterized by axonal degeneration and gliosis [9]. The disease affects young adults, mostly between 20 and 40 years old, with a predominance for the female sex. Cases present a wide range of symptoms with varying severity $[9,10]$. In general, MS starts with a relapsing-remitting course characterized by sensory disturbances, unilateral optic neuritis, and diplopia. While these signs typically stabilize over a period of several days, the persisting signs of CNS dysfunction become dominant, leading to irreversible disability and cognitive deficits [9]. In addition, there are acute forms of MS, such as the Marburg type, the Balo'type (concentric sclerosis), and the Schilder type, all of which are virulent, fulminant and may quickly lead to death [11]. MS can also manifest in childhood, and pediatric MS has a substantial impact on the health-related and overall quality of a lifetime [12].

The causes of MS, while not fully elucidated, involve genetic susceptibility (strongest influence coming from the HLA class II locus) and environmental exposures (such as infectious mononucleosis, Epstein-Barr virus infection and lack of sun exposure/vitamin D) [13]. Although the pathophysiological mechanisms of MS remain largely unknown, studies have implicated autoreactive $\mathrm{T}$ cells (primarily, $\mathrm{T}$ helper (Th)- $1 \mathrm{CD}^{+}{ }^{+} \mathrm{T}$ cells and

(c) The Author(s). 2018 Open Access This article is distributed under the terms of the Creative Commons Attribution 4.0 International License (http://creativecommons.org/licenses/by/4.0/), which permits unrestricted use, distribution, and 
Th17 cells) as being involved, particularly through their secretion of cytokines and activation of the inflammatory cascade; the eventual result is demyelinating plaquesthe pathological hallmark of MS. The inflammatory demyelination process triggers microglia activation and chronic oxidative injury, leading to neurodegeneration and, ultimately, axonal and neuronal death [13].

To date, the diagnosis of MS is based upon clinical evidence. In many situations, however, early symptoms of MS can be nonspecific, being suggestive of many other disorders of the CNS. Magnetic resonance imaging can assist in the diagnosis, but a simple specific laboratory test will be much more convenient and affordable for identifying or ruling out MS. A current priority of the MS research field is to find specific biomarkers that will improve the clinical diagnosis of MS and provide further insight into its pathophysiological mechanisms. Considering MS as a typical autoimmune disease and that ncRNAs contribute to immune regulation and pathogenesis of other autoimmune diseases, an increasing number of research groups have sought to identify ncRNAs that can predict the disease activity and its progression.

In this review of the peer-reviewed literature, we present the most recent findings for ncRNAs in MS pathogenesis and discuss the related molecular mechanisms, particularly from the perspective of how these data support the potential of ncRNAs in clinical applications for diagnosis and treatment.

\section{Biology and primary function of ncRNAs MiRNAs}

MiRNAs are highly expressed in cells of the immune system, CNS and tumors, wherein they regulate the expression of target genes in a sequence-specific manner [14]. The biogenesis of miRNAs begins in the nuclear compartment, where RNA polymerase (Pol) II produces the primary (pri)-miRNA transcripts. The pri-miRNAs are then further processed by the enzyme Drosha and its partner protein DiGeorge syndrome critical region 8 to generate one or more precursor (pre)-miRNAs. The pre-miRNAs are then exported from the nucleus to the cytoplasm by exportin-5/RanGTP, where they are digested by Dicer acting with the trans-activator RNA binding protein. The resultant mature miRNAs (21-25 nt in length; double-stranded duplex) are incorporated into the AGO proteins, forming the RNA-induced silencing complex (RISC). In the RISC, the miRNA duplex is unwound by helicase, and one strand (the "passenger" strand) of this duplex is degraded. The remaining strand (the "guide" strand) then binds to the 3 '-untranslated region of its target mRNAs, thereby resulting in degradation or translational repression [15, 16] (Fig. 1).
MiRNA-mediated regulation of gene expression has been implicated in a broad range of biological pathways, such as hematopoiesis, organogenesis, cell differentiation, proliferation, and apoptosis [14, 17-19]. It is estimated that miRNAs target 33\% of human genes [20], together forming a complex regulatory network that underlies both physiological and pathological processes, with the potential to both benefit (i.e., normal cell growth) and harm (i.e., cancer) [21]. Indeed, studies have begun to reveal the contributions of miRNAs to the dysregulated gene expressions in human autoimmune diseases, including MS.

\section{LncRNAs}

The lncRNAs have been categorized according to their genomic organization, including in relation to protein coding genes. In addition to the long-standing categories of sense lncRNAs, antisense lncRNAs, intronic lncRNAs, intergenic lncRNAs, and enhancer RNAs [22, 23], the circular (circ) RNAs have been recently identified. This new class of lncRNAs features a covalently closed continuous loop without 5 ' - or 3 '-polarity and has been detected in a wide array of eukaryotic organisms [24-26]. Although the precise origins remain unknown [27], the biogenesis of lncRNAs can occur in either the nuclear or cytoplasmic compartments [28], in contrast to the miRNAs (discussed above). However, like the miRNAs, most lncRNAs are transcribed by Pol II; the others are likely being transcribed by Pol III [23] (Fig. 1).

The collective in-depth studies of lncRNAs have identified an unexpected abundance in the human genome, with several lncRNA databases having been established. The lncRNAs were initially thought to be spurious transcriptional noise resulting from low RNA polymerase fidelity [27, 29], but the advent of high-throughput sequencing has revealed biological functions for many. These include the extensively studied Xist (functioning in X-chromosome inactivation) [30, 31], H19 (genomic imprinting) [32], and HOTAIR (tumor development and progression) [33, 34]. LncRNA-mediated regulation has been identified in almost every step of gene expression; for instance, lncRNAs can regulate gene expression through affecting transcriptional, post-transcriptional, and translational processes; apoptosis; and intracellular trafficking [27, 35-38] by acting as a reservoir of miRNA sponges, protein decoys, and molecular scaffolds [39]. The most recent studies have provided evidence to suggest such functions in autoimmune diseases such as MS [40, 41].

\section{MiRNAs in MS}

\section{Biomarkers of miRNAs in MS}

The development of miRNA profiling techniques has greatly facilitated prospective biomarker studies in MS. 


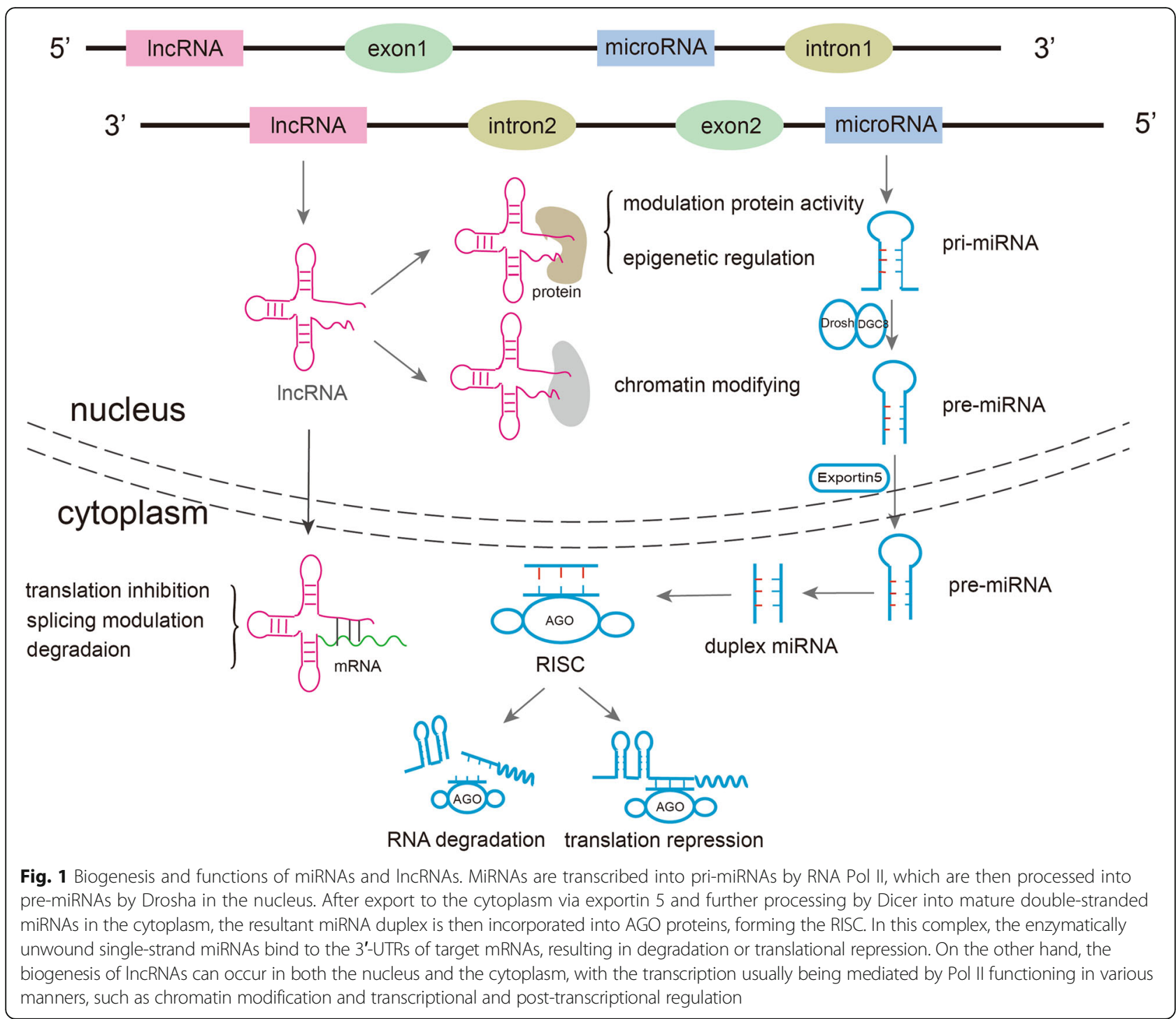

To date, a number of miRNA expression profiling studies have been published, in which their potentials as prognostic and diagnostic biomarkers of MS have been evaluated (Table 1).

Studies of blood from MS patients have yielded differential miRNA expression profiles with relation to disease status. The first study [42] analyzed the expression patterns of 364 miRNAs in peripheral blood mononuclear cells (PBMCs) from MS patients in relapse and in remission, as well as in healthy controls. A relapse phase-specific miRNA signature was found, showing strong dysregulation of miR-18b and miR-599. The remission phase-specific miRNA signature showed a strong dysregulation of miR-96. The study also yielded a set of miRNAs considered good candidates for future biomarker studies in MS and at least two more miRNAs with good potential for characterizing the relapse status, even though the exact mechanism of the latter remains unclear. Subsequent studies confirmed altered expression of the MS-related miRNAs miR-326, hsa-miR-145, and miR-17-5p in PBMCs and $\mathrm{CD}^{+}{ }^{+} \mathrm{T}$ cells of relapsing MS patients [43-45]. In addition, 23 MS-related differentially expressed miRNAs were found to be related to a predominance of upregulated genes in $\mathrm{CD} 4^{+}$regulatory T cells of patients [46].

MS-related differential expression of miRNAs have also been observed in patient sera. Such a detection method is particularly attractive as a convenient means for diagnosing or prognosing disease cases [47-52]. The miRNAs with promise for such research and development include miR-15b, miR-23a and miR-223 (significantly decreased in MS sera vs healthy controls), miR-155 and miR-301a (decreased), and miR-326 (increased in relapsing-remitting (RR) MS sera) [51]. In addition, some exosomal miRNAs in sera have been identified as differentially expressed between RRMS and 
Table 1 MiRNAs dysregulated in MS and possible underlying mechanisms

\begin{tabular}{|c|c|c|c|c|c|}
\hline Source of miRNA & Research model & Change & Target & Function & Ref \\
\hline \multicolumn{6}{|l|}{$\overline{P B M C}$} \\
\hline hsa-miR-18b, hsa-miR-599, hsa-miR-96 & Human & $\uparrow$ & ND & ND & [42] \\
\hline miR-590 & Human & $\uparrow$ & Tob1 & Promote Th17 differentiation & [63] \\
\hline $\operatorname{miR}-448$ & Human & $\uparrow$ & PTPN2 & Promote Th17 differentiation & [64] \\
\hline miR-21, miR-146a, miR-146b & Human & $\uparrow$ & ND & ND & [95] \\
\hline miR-140-5p & Human & $\downarrow$ & STAT1 & Inhibit Th1 differentiation & [69] \\
\hline \multicolumn{6}{|l|}{$\mathrm{CD}^{+} \mathrm{T}$ cell } \\
\hline miR-326 & C57BL/6 mice, human & $\uparrow$ & Ets-1 & Promote Th17 differentiation & [43] \\
\hline miR-155 & C57BL/6 mice, human & $\uparrow$ & Est- 1 and Jarid2 & Promote Th17/Th1 differentiation & [59-62] \\
\hline miRNA let-7e & C57BL/6 mice & $\uparrow$ & IL-10 & Promote Th17 differentiation & [65] \\
\hline miR27a & Human & $\uparrow$ & ND & $\begin{array}{l}\text { Inhibit negative regulators of Th17 } \\
\text { cell differentiation? }\end{array}$ & [66] \\
\hline miR-128, miR-27b, miR-340 & C57BL/6 mice human & $\uparrow$ & BMI1? IL-4 & $\begin{array}{l}\text { Promote Th1 differentiation and } \\
\text { inhibit Th2 differentiation }\end{array}$ & [70] \\
\hline $\operatorname{miR}-17-5 p$ & Human & $\uparrow$ & ND & ND & [45] \\
\hline $\operatorname{miR}-214$ & Human & $\downarrow$ & ND & ND & [66] \\
\hline miR-15b & C57BL/6 mice human & $\downarrow$ & OGT & Inhibit Th17 differentiation & [67] \\
\hline miR-132 & C57BL/6 mice & $\downarrow$ & ND & Suppress T cell proliferation & [68] \\
\hline \multicolumn{6}{|l|}{ B cell } \\
\hline miR-320a & Human & $\downarrow$ & MMP-9 & $\begin{array}{l}\text { Disrupt the blood-brain barrier and } \\
\text { digest myelin basic protein }\end{array}$ & [71] \\
\hline miR-132 & Human & $\uparrow$ & Sirtuin-1 & ND & [75] \\
\hline miR-106b-25 cluster, miR-17-92 cluster & Human & $\downarrow$ & PI3K? PTEN? & ND & [74] \\
\hline \multicolumn{6}{|l|}{ Serum/plasma } \\
\hline miR-326 & Human & $\uparrow$ & ND & ND & [51] \\
\hline $\begin{array}{l}\text { miR-614, miR-572, miR-648, miR-1826, } \\
\text { miR-422a, miR-22 }\end{array}$ & Human & $\uparrow$ & ND & ND & [52] \\
\hline miR-24 and miR-137 & Human & $\uparrow$ & ND & ND & [47] \\
\hline miR-15b, miR-23a, miR-223 & Human & $\downarrow$ & ND & ND & [48] \\
\hline miR-155, miR-301a & Human & $\downarrow$ & ND & ND & [51] \\
\hline miR-1979 & Human & $\downarrow$ & ND & ND & [52] \\
\hline has-miR-let-7a, miR-648a & Human & $\downarrow$ & ND & ND & [50] \\
\hline \multicolumn{6}{|l|}{ Exosome } \\
\hline $\begin{array}{l}\text { miR-15b-5p, miR-23-3p, miR-223-3p, } \\
\text { miR-30b-5p, miR-342-3p, miR-432-5p }\end{array}$ & Human & $\uparrow$ & ND & ND & [53] \\
\hline \multicolumn{6}{|l|}{ Microglia } \\
\hline miR-155 & Human & $\uparrow$ & ND & ND & [77] \\
\hline miR-124 & C57BL/6 mice & $\downarrow$ & ND & $\begin{array}{l}\text { Promote the } \mathrm{M} 2 \text { phenotype of } \\
\text { macrophages and microglia }\end{array}$ & [76] \\
\hline \multicolumn{6}{|l|}{ Active lesions } \\
\hline miR-34a, miR-155, miR-326 & Human & $\uparrow$ & CD47 & Promote phagocytosis of myelin & [80] \\
\hline \multicolumn{6}{|l|}{ CSF } \\
\hline miR-922 & Human & $\downarrow$ & ND & ND & [54] \\
\hline miR-181c, miR-633 & Human & $\uparrow$ & & & \\
\hline miR-219 & Human & $\downarrow$ & ND & ND & [55] \\
\hline miR-150 & Human & $\uparrow$ & ND & ND & [56] \\
\hline
\end{tabular}


Table 1 MiRNAs dysregulated in MS and possible underlying mechanisms (Continued)

\begin{tabular}{llllll}
\hline Source of miRNA & Research model & Change & Target & Function & Ref \\
\hline $\begin{array}{l}\text { Demyelinated MS hippocampi } \\
\text { miR-124 }\end{array}$ & Human & $\uparrow$ & AMPA2 & ND \\
& & AMPA3 & & [96] \\
\hline
\end{tabular}

ND not determined; $\uparrow$, upregulation; $\downarrow$, downregulation;?, presumed

progressive MS [53]. Ultimately, comparisons between the two clinically distinct MS subtypes-RRMS and progressive MS-identified nine miRNAs with significant differential expression, namely miR-15b-5p, miR-23a-3p, miR-223-3p, miR-374a-5p, miR-30b-5p, miR-433-3p, miR-485-3p, miR-342-3p, and miR-432-5p. The finding of miRNAs associated with circulating exosomes suggests a potential for their development as informative biomarkers, not only for distinguishing MS cases from healthy controls but also in predicting disease subtype with accuracy.

According to the MS characteristic as a demyelinating neurodegenerative disorder, disease-specific miRNA biomarkers in cerebrospinal fluid (CSF) could also be of great significance. In an analysis of miRNAs in CSF of MS patients, Haghikia et al. [54] found that miR-922, miR-181c, and miR-633 were differentially regulated, as compared to expression levels detected in patients with other neurologic diseases. In a more recent focused investigation of the levels of miR-219 in CSF in relation to MS diagnosis, MS patients were found to have the highest rate of undetectable miR-219 compared to controls; in addition, a strong positive association was found between the undetectable level of miR-219 and diagnosis of MS, suggesting its potential as a biomarker for MS diagnosis [55]. Yet, another study in recent years identified miR-150 in CSF as a putative novel biomarker of active inflammatory disease, suggesting its potential for early diagnosis of MS [56].

Interestingly, infectious pathogens can produce miRNAs in patient serum, easily detectable by standard PCR. For instance, the CNS- and gut-selective immunosuppressant natalizumab is one of the most effective therapies for active RRMS, but its long-term use is associated with development of progressive multifocal leucoencephalopathy, a serious opportunistic brain infection caused by a neurotropic strain of the JC virus [57]. When Basnyat and colleagues [58] investigated plasma of natalizumab-treated MS patients, they determined that the presence of JC polyoma virus miRNA in plasma may indicate asymptomatic viral infection and concluded that the virus-encoded miRNAs may hold promise as risk assessment biomarkers for progressive multifocal leucoencephalopathy in MS.

\section{MiRNAs involved in MS pathogenesis Regulation of immune cells}

Proinflammatory responses mediate autoimmune demyelination in MS. As such, the potential effects and underlying mechanisms of miRNAs have been investigated extensively for the MS-related immune cell types, namely the $\mathrm{CD}^{+} \mathrm{T}$ cells, $\mathrm{B}$ cells, and macrophages (Fig. 2).

Th17 and Th1 cells Increasing evidence has indicated that miRNA might exert their effects on Th17/Th1 cells by influencing their differentiation and function. The MS-related upregulated miRNAs can inhibit negative regulators of Th17/Th1 cell differentiation, and vice versa for the downregulated miRNAs. In the pioneer study about the role of miRNAs in T cells in MS, Du et al. [43] found that miR-326 expression was associated with IL-17-producing Th17 cells, key factors in the pathogenesis of MS. Specifically, miR-326 was found to be overexpressed in Th17 cells of patients with RRMS and to promote Th17 cell differentiation by inhibiting Ets-1, a negative regulator of Th-17 differentiation. In other studies, increased miR-155 expression was found within $\mathrm{T}$ cells and shown to promote Th17/Th1 differentiation similarly, by targeting the transcription factor Ets-1 [59-61]. Finally, the miR-155 was found to control Th17 cell function by suppressing the inhibitory effects of Jarid2, a DNA-binding protein that recruits the chromatin modifier polycomb repressive complex 2 to the chromatin [62].

The increased miRNAs in MS might promote Th17 differentiation through other mechanisms as well. Liu et al. [63] reported that miR-590 was increased in relapse cases of MS and demonstrated that miR-590 promotes pathogenic Th17 cell differentiation through targeting of Tob1, a member of the tob/btg1 family of antiproliferative proteins. They also found that the overexpression of miR-590 increased the pathogenicity of Th17 cells by upregulating several inflammationassociated molecules, such as CXCL3, CSF2, and IL-23R. $\mathrm{Wu}$ et al. [64] reported that miR-448 was significantly increased in MS patients and demonstrated its promotion of MS development through induction of the Th17 response by targeting the protein tyrosine phosphatase non-receptor type 2 (PTPN2). Guan et al. [65] reported that the level of miRNA let-7e was significantly upregulated in the experimental autoimmune encephalomyelitis (EAE) model of MS, showing the expression as being mainly in $\mathrm{CD} 4^{+} \mathrm{T}$ cells and with function in enhancement of Th1 and Th17 cells to aggravate EAE, probably 


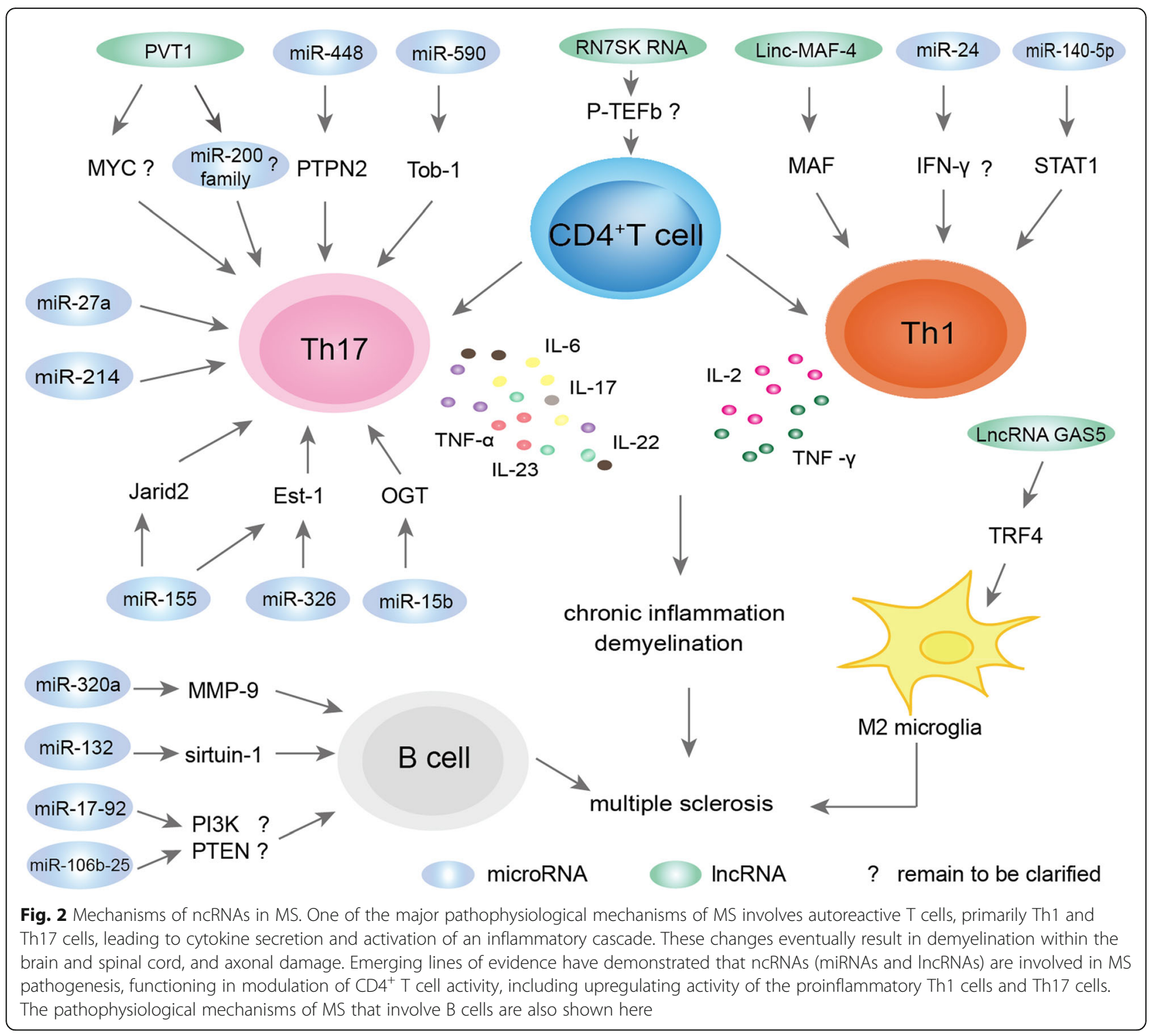

by targeting IL-10. Finally, Ahmadian-Elmi et al. [66] demonstrated that miR-27a was increased in relapsing cases of MS and suggested that such may inhibit the negative regulators of Th17 cell differentiation.

Downregulated miRNAs in MS have also been reported and appear to influence Th17/Th1 differentiation similar to the upregulated miRNAs. For example, Liu et al. [67] reported downregulated expression of miR-15b in $\mathrm{CD} 4^{+} \mathrm{T}$ cells obtained from patients with MS and mice with EAE, and demonstrated a consequent inhibition of Th17 differentiation through targeting of O-linked $\mathrm{N}$-acetylglucosamine transferase (OGT), with subsequent effects on the transcriptional regulation of RORyt through O-GlcNAcylation of NF-kB. Hanieh et al. [68] reported that the expression of miR-132 was downregulated in $\mathrm{CD}^{+}{ }^{+}$cells and associated with EAE severity; miR-132 silencing in vivo abolished 2,3,7,8-tetrachlorodibenzo-pdioxin-induced cholinergic anti-inflammation and aggravated $\mathrm{EAE}$, while its overexpression in encephalitogenic $\mathrm{CD}^{+} \mathrm{T}$ cells decreased IL-17 and IFN- $\gamma$ and suppressed $\mathrm{T}$ cell proliferation, indicating its effects on the functions of Th1 and Th17 cells. Guan et al. [69] demonstrated that the miR-140-5p was markedly downregulated in MS, and results of further investigation strongly suggested that this miRNA inhibits Th1 differentiation through downregulation of the signal transducer and activator of transcription 1 (STAT1) gene. As such, the downregulation of miR140-5p leads to enhanced development of Th1 cells and MS disease severity. Finally, the study by Ahmadian-Elmi et al. [66] discussed above also found that miR-214 was downregulated in the relapsing phase of MS and theorized to inhibit Th17 differentiation in MS. 
Naïve and memory $\mathrm{CD}^{+} \mathrm{T}$ cells In a study of $\mathrm{CD} 4^{+} \mathrm{T}$ cells from MS patients, Guerau-de-Arellano and colleages [70] found increased miR-128 and miR-27b in the naive cell subset and miR-340 in the memory cell subset. These miRNAs were also found to synergistically promote Th1 differentiation and inhibit Th2 cell differentiation. Moreover, the underlying mechanisms were shown to involve direct suppression of the expression of B lymphoma Mo-MLV insertion region 1 homolog (BMI1) and IL-4, resulting in decreased GATA3 levels and the imbalance of Th2 and Th1 populations. The study applied this knowledge as treatment in vitro, exposing MS patient T cells to inhibitors of these miRNAs, with the result of restoring the Th2 responses.

B cells Similar to the findings in T cells, studies of dysregulated miRNAs in $\mathrm{B}$ cells also uncovered contributions to the pathogenesis of MS. Aung et al. [71] reported that miR-320a was significantly downregulated in B cells of MS patients and demonstrated that matrix metallopeptidase-9 (MMP-9) was consequently increased significantly in B cells. MMP-9 is able to disrupt the blood-brain barrier and to digest myelin basic protein [72, 73]; increased expression and secretion of MMP-9 in B cells may contribute to damaging the blood-brain barrier and myelin destruction, thereby contributing to MS pathogenesis. In addition, Sievers et al. [74] found 10 distinct differentially expressed miRNAs in B cells from untreated MS patients compared with natalizumab-treated MS patients; among these miRNAs, the miR-106b-25 cluster and miR-17-92 cluster were particularly deregulated. Furthermore, miRNA-mRNA interaction analysis revealed that $\mathrm{B}$ cell receptor, phosphatidyl-inositol-3-kinase (PI3K), and phosphatase and tensin homology (PTEN) are the most affected signaling pathways in B cells of MS patients. Finally, Miyazaki et al. [75] found overexpression of miR-132 in B cells of MS patients and speculated that a novel miRNA-132/surtuin-1 axis may underlie the aberrant B cell cytokine regulation in patients with RRMS.

Macrophages Macrophages and microglial cells (considered as CNS-resident macrophages) may also be involved in MS [76]. The expression of miR-155 was reported as significantly increased in both peripheral circulating $\mathrm{CD}_{14}{ }^{+}$monocytes and $\mathrm{CD} 68^{+}$cells of active lesions from MS patients compared to those taken from control donors [77]. Ponomarev et al. [78] reported that miR-124 was downregulated in activated microglia during EAE. MiR-124 is a key regulator of microglia quiescence in the CNS and, thus, is an important modulator of monocyte and macrophage activation, contributing to the M2 phenotype of macrophages and microglia in the periphery during EAE. In the same study, transfection of macrophages with miR-124 was found to cause downregulation of M1-associated effector molecules, such as TNF- $\alpha$, and upregulation of M2-related effector molecules, such as TGF- $\beta$, arginase-1, and FIZZ1 [78]; these changes would confer the M2 phenotype in MS, establishing a profile crucial for the suppression of EAE.

PBMCs Genetic susceptibility is highly correlated with the etiology of MS. Most recently, Luo et al. [79] identified 21 differentially expressed miRNAs in PBMCs from MS patients, as compared with PBMCs from healthy controls; these included miR-199a and miR-142-3p. By using biological information analysis, they constructed a network of these miRNAs and their susceptibility genes and found that KRAS (a vital MS susceptibility gene) is a predictive target of miR-199a. In addition, miR-142-3p (a key negative regulator of IL-1 $\beta$-dependent synaptopathy in neuroinflammation) was predicted to target both IL7R and KRAS genes. Collectively, these results suggest that miR-199a, miR-142-3p, and their target genes-particularly the IL7R and KRAS genes-might serve as MS therapeutic targets in the MAPK /JAK-STAT signaling transduction pathway.

\section{Direct influence of CNS cells}

In recent years, multiple studies have identified miRNAs with high-level expression in the CNS under physiologic conditions. Characterization of these miRNAs has revealed functions in establishing an environment that supports remyelination and axon regeneration. Based on the characteristics of MS, understanding the dysregulation and functions of miRNAs in the CNS will likely benefit our understanding of the pathogenesis of MS and translation of that knowledge to clinical applications.

Astrocytes are one of the cell types participating in MS plaque formation. Using laser capture microdissection to analyze cell type-specific miRNA profiles, Junker et al. [80] determined that astrocytes contained all 10 of the miRNAs that were most strongly upregulated in active MS lesions. Among these 10, miR-155, miR-34a, and miR-326 were predicted to target CD47, ultimately serving to release macrophages from inhibitory control and subsequently promoting phagocytosis of myelin [80].

Damage to oligodendrocytes (OLs) can lead to demyelination and hinder effective neural communication, both being features associated with MS. A murine-based study by Dugas et al. [81] indicated that multiple miRNAs might act as a positive feedback loop to coordinate rapid transition of gene expression during OL differentiation (i.e., miR-219, miR-338, miR-23, and miR-9), proliferation (i.e., miR-17-5p and miR-19b), and myelination at multiple stages of the disease process. The study also characterized the role of miR-219 in maintenance of lipids and redox homeostasis in mature OLs, showing 
the involvement of binding to ELOVL7 and indicating that persistent miRNA expression is required for maintenance of the myelin sheath [81]. The essential roles of miR-17-5p and miR-19b in controlling the number of OLs, through targeting of PTEN (an inhibitor of PI3K signaling, and a negative regulator of cell proliferation in RRMS patients), had been shown by another group [45]. In addition, miR-23 regulation of lamin B1 was demonstrated as crucial for OL development and myelination by an earlier study [82], supporting its potential role in the pathogenic mechanism of MS.

\section{LncRNAs in MS}

\section{MS-related IncRNAs as biomarkers}

The lncRNAs and their abilities to control expression of genes, as well as their contributions to pathogeneses of diseases, have only recently been recognized. Although the research into lncRNAs' involvement in MS, in particular, is only in its infancy, aberrant lncRNA expression has been observed in human cases.

Santoro et al. [83] identified three lncRNAs upregulated in the serum of RRMS patients, namely the nuclear paraspeckle assembly transcript 1 (NEAT1), taurine upregulated 1 (TUG1), and 7SK small nuclear (RN7SK RNA). Zhang et al. [84] further investigated the expression of lncRNAs in PBMCs of patients with MS and identified six aberrant lncRNAs, consisting of three upregulated (LncRNA ENSG00000231898.3, IncRNA XLOC_009626, and IncRNA XLOC_010881) and three downregulated (LncRNA ENSG00000233392.1, lncRNA
ENSG00000259906.1, and lncRNA XLOC_010931). Last year, Eftekharian et al. [85] identified another three aberrantly expressed lncRNAs in the circulating blood cells of RRMS patients, as compared to samples from healthy controls; these included downregulated lncRNAs (PVT1 and FAS-AS1) and an upregulated lncRNA (THRIL). Although it remains unknown how these lncRNAs may be involved in MS pathogenesis, their aberrant expression profile suggests their candidacy as MS-specific biomarkers for predication of disease course or treatment response (Table 2).

\section{LncRNAs involved in MS pathogenesis}

Recently, several lncRNAs have been verified as involved in MS pathogenesis (Table 2 and Fig. 2). It is well known that a proinflammation response is the primary cause of MS development and that a cellular profile of high-M1 versus low-M2 polarized microglia is a pivotal feature of MS pathogenesis [86]. As such, Sun et al. [87] performed a microarray screen and found that the lncRNA GAS5 was significantly upregulated in amoeboid-shaped microglia of MS patients and that this feature was significantly associated with MS. Subsequent functional studies in mice with EAE revealed that IncRNA GAS5 suppresses the transcription of TRF4, a key factor controlling M2 polarization, by recruiting the polycomb repressive complex 2, thereby inhibiting M2 polarization. Furthermore, interference with lncRNA GAS5 in transplanted microglia was found to attenuate the progression of EAE and to

Table 2 Dysregulated IncRNAs in MS

\begin{tabular}{|c|c|c|c|c|c|}
\hline Source of IncRNA & Research model & Change & Target & Function & Ref \\
\hline \multicolumn{6}{|l|}{ PBMC } \\
\hline THRIL & Human & $\uparrow$ & ND & ND & \multirow[t]{3}{*}[85,97,98]{} \\
\hline FAS-AS1 & Human & $\downarrow$ & ND & ND & \\
\hline PVT1 & Human & $\downarrow$ & MYC, miR-200 family & ND & \\
\hline IncRNA ENSG00000231898.3 & Human & $\uparrow$ & ND & ND & [84] \\
\hline IncRNA XLOC_009626 & Human & $\uparrow$ & ND & ND & [84] \\
\hline IncRNA XLOC_010881 & Human & $\uparrow$ & ND & ND & [84] \\
\hline IncRNA ENSG00000233392.1 & Human & $\downarrow$ & ND & ND & [84] \\
\hline IncRNA ENSG00000259906.1 & Human & $\downarrow$ & ND & ND & [84] \\
\hline IncRNA XLOC_010931 & Human & $\downarrow$ & ND & ND & [84] \\
\hline linc-MAF-4 & Human & $\uparrow$ & MAF & $\uparrow$ Th1 differentiation, $\downarrow$ Th2 differentiation & [91] \\
\hline \multicolumn{6}{|l|}{ Serum } \\
\hline NEAT1 & Human & $\uparrow$ & ND & ND & [83] \\
\hline TUG1 & Human & $\uparrow$ & ND & ND & [83] \\
\hline RN7SK RNA & Human & $\uparrow$ & PTEF-b? & ND & [83] \\
\hline \multicolumn{6}{|l|}{ M2-type microglia } \\
\hline IncRNA GAS5 & C57BL/6 mice & $\uparrow$ & TRF4 & $\downarrow$ M2 polarization & [87] \\
\hline
\end{tabular}

$N D$ not determined; $\uparrow$, upregulation; $\downarrow$, down-regulation;?, presumed 
promote remyelination, suggesting this lncRNA as a promising target for MS treatment.

Increasing evidence supports the involvement of the proinflammatory cells Th1 and Th17 in the disease course of MS [88]. As such, interfering with the Th cell population, such as by expansion of Th2 cells or inhibition of Th1/Th17 cells, was hypothesized to help resolve MS; indeed, murine model studies showed that these approaches ameliorated EAE [89, 90]. Last year, Zhang et al. [91] reported that linc-MAF-4 was increased significantly in PBMCs of patients with MS, as compared to healthy controls, and that increasing the levels significantly facilitated Th1 differentiation and inhibited Th2 differentiation by directly inhibiting MAF, a Th2 cell transcription factor. In contrast, downregulation of linc-MAF-4 was found to inhibit development of Th1 cells and to heighten the development of Th2 cells. Therefore, by targeting MAF to regulate Th1/Th2 differentiation, linc-MAF-4 increased the in vivo Th1/Th2 ratio and promoted MS pathogenesis, suggesting its potential as a therapeutic target for MS.

\section{CircRNAs in MS}

CircRNAs, a novel family of ncRNAs, have emerged as the newest player in the complex network of gene expression regulation. Though circRNAs have been implicated in several types of diseases [92], there are only two published studies to date involving circRNAs analysis in MS patients. While investigating alternative splicing abnormalities in the GSDMB gene, Cardamone et al. [93] found an upregulated circRNA (hsa_circ_0106803) in the PBMCs of RRMS patients and identified resultant novel isoforms of the GSDMB gene. Almost at the same time, Iparraguirre et al. [94] were carrying out circRNA expression profiling of peripheral blood leucocytes from MS patients and healthy controls; the comparative analysis and subsequent validation experiments revealed that circ_0005402 and circ_0035560 are downregulated in MS patients. While it remains unknown whether these MS-related circRNAs are involved in the process of MS development, the data support their further study as blood biomarkers for MS disease.

\section{Conclusion and perspectives}

The pathophysiological and clinical complexity of MS underlies the urgent need for a great variety of potential biomarkers specific for diagnosis, prediction of disease course, and treatment. Emerging evidence indicates the potential of ncRNAs in the regulation of gene expression, providing new opportunities to understand the course of various diseases, including MS. Indeed, multiple ncRNAs have been found to be expressed differentially in diseased patients compared with healthy controls, and some ncRNAs have been verified as involved in MS pathogenesis, through various mechanisms. The collective findings have served to indicate their potential value as diagnostic and predictive markers in MS (Table 3).

The field of research exploring ncRNAs in MS, however, requires further attention, particularly for confirmation before the findings can be translated to clinical applications; this is especially the case for the circRNAs, the newest promising ncRNAs subtype, which have not been explored extensively in MS yet which might be one of the key research goals in next few years. In addition, the exact effects of various ncRNAs on the course of diseases need to be clarified. The key underlying mechanisms, including sponging and RNA and protein binding for disease-specific ncRNAs, have to be explored comprehensively. Furthermore, novel mechanisms such as protein translation capacity of circRNAs and other unknown mechanisms remain to be explored, although such knowledge will expand our understanding of the essence of diseases and more importantly facilitate the design of reasonable therapeutic strategies against various diseases that threaten human health.

Table 3 Published values of Sn, Sp, and AUC for biomarker candidates for MS

\begin{tabular}{|c|c|c|c|c|c|}
\hline NcRNA subtype within & NcRNA name & $\mathrm{Sn}$ & Sp & $A \cup C$ & Ref \\
\hline \multicolumn{6}{|l|}{ MicroRNAs } \\
\hline Blood cells & hsa-miR-145 & $90.0 \%$ & $89.5 \%$ & 0.96 & {$[44]$} \\
\hline \multirow[t]{4}{*}{ Serum/plasma } & miR-223 & ND & ND & 0.80 & [48] \\
\hline & miR-15b & ND & ND & 0.75 & [48] \\
\hline & $\operatorname{miR}-24$ & ND & ND & 0.686 & [47] \\
\hline & miR-137 & ND & ND & 0.741 & {$[47]$} \\
\hline \multirow[t]{9}{*}{ Exosome } & miR-15b-5p & ND & ND & 0.76 & [53] \\
\hline & $\operatorname{miR}-23 a-3 p$ & ND & ND & 0.80 & [53] \\
\hline & miR-223-3p & ND & ND & 0.77 & [53] \\
\hline & miR-374a-5p & ND & ND & 0.78 & [53] \\
\hline & miR-30b-5p & ND & ND & 0.82 & [53] \\
\hline & miR-433-3p & ND & ND & 0.93 & [53] \\
\hline & miR-485-5p & ND & ND & 0.87 & [53] \\
\hline & miR-342-3p & ND & ND & 0.81 & [53] \\
\hline & miR-432-5p & ND & ND & 0.86 & [53] \\
\hline \multirow[t]{4}{*}{ CSF } & miR-181c & ND & ND & 0.73 & {$[54]$} \\
\hline & miR-922 & ND & ND & 0.74 & {$[54]$} \\
\hline & miR-633 & ND & ND & 0.82 & {$[54]$} \\
\hline & miR-150 & $89 \%$ & $50 \%$ & 0.744 & [56] \\
\hline \multicolumn{6}{|l|}{ CircRNAs } \\
\hline \multirow[t]{2}{*}{ PBMCs } & circ_0005402 & $94.4 \%$ & $75.0 \%$ & 0.899 & [94] \\
\hline & circ_0035560 & $55 \%$ & $88.9 \%$ & 0.706 & [94] \\
\hline
\end{tabular}

Sn sensibility, Sp specificity, AUC area under the curve, PBMCs peripheral blood mononuclear cells, ND not determined 


\section{Abbreviations}

circRNA: Circular RNAs; CNS: Central nervous system; EAE: Experimental autoimmune encephalomyelitis; IncRNAs: Long ncRNAs; miRNAs: Micro RNAs; MMP-9: Matrix metallopeptidase-9; MS: Multiple sclerosis; ncRNAs: Noncoding RNAs; NEAT1: Nuclear paraspeckle assembly transcript 1; nt: Nucleotides; PBMCs: Peripheral blood mononuclear cells; Pol: RNA polymerase; premiRNAs: Precursor miRNAs; pri-miRNAs: Primary miRNA; PTPN2: Tyrosine phosphatase non-receptor type 2; RN7SK RNA: 7SK small nuclear; RRMS: Relapsing-remitting MS; Th: T helper; TUG1: Taurine upregulated 1

\section{Acknowledgements}

Not applicable.

\section{Funding}

This work was supported by the National Key R\&D Program of China (No. 2016YFA0502203) and the National Foundation of China (No. 81670534).

\section{Availability of data and materials}

Not applicable.

\section{Authors' contributions}

$X Y$ and $Y W$ researched the literature and drafted the manuscript. BZ and BN critically reviewed and edited the work. All authors read and approved the final manuscript.

\section{Ethics approval and consent to participate}

Not applicable.

\section{Consent for publication}

Not applicable.

\section{Competing interests}

The authors declare that they have no competing interests.

\section{Publisher's Note}

Springer Nature remains neutral with regard to jurisdictional claims in published maps and institutional affiliations.

\section{Author details}

${ }^{1}$ Department of Immunology, Medical College of Qingdao University, 308 Ningxia Road, Shinan District, Qingdao 266003, China. ${ }^{2}$ Department of Pathophysiology, Third Military Medical University, 30 Gaotanyan St. Shapingba District, Chongqing 400038, China. ${ }^{3}$ Institute of Immunology of PLA, Third Military Medical University, 30 Gaotanyan St., Shapingba District, Chongqing 400038, China.

Received: 1 July 2018 Accepted: 14 November 2018 Published online: 29 November 2018

\section{References}

1. Gibb EA, Brown CJ, Lam WL. The functional role of long non-coding RNA in human carcinomas. Mol Cancer. 2011;10:38.

2. Consortium EP. An integrated encyclopedia of DNA elements in the human genome. Nature. 2012;489:57-74

3. Costa FF. Non-coding RNAs: meet thy masters. BioEssays. 2010:32:599-608.

4. Okada Y, Muramatsu T, Suita N, Kanai M, Kawakami E, lotchkova V, Soranzo $\mathrm{N}$, Inazawa J, Tanaka T. Significant impact of miRNA-target gene networks on genetics of human complex traits. Sci Rep. 2016;6:22223.

5. Brosnan $C A$, Voinnet $O$. The long and the short of noncoding RNAs. Curr Opin Cell Biol. 2009;21:416-25.

6. Lau NC, Seto AG, Kim J, Kuramochi-Miyagawa S, Nakano T, Bartel DP, Kingston RE. Characterization of the piRNA complex from rat testes. Science. 2006:313:363-7.

7. Wright MW, Bruford EA. Naming 'junk': human non-protein coding RNA (ncRNA) gene nomenclature. Hum Genomics. 2011;5:90-8.

8. Esteller M. Non-coding RNAs in human disease. Nat Rev Genet. 2011;12: 861-74

9. Thompson AJ, Baranzini SE, Geurts J, Hemmer B, Ciccarelli O. Multiple sclerosis. Lancet. 2018;391:1622-36.

10. Confavreux C, Vukusic S. The clinical course of multiple sclerosis. Handb Clin Neurol. 2014;122:343-69.
11. Jasperson J, Jones AG. A case of rapid deterioration: acute multiple sclerosis of the Marburg type. J Neurosci Nurs. 1998:30:350-5.

12. Hintzen $R Q$, van Pelt DE. Paediatric MS is the same disease as adult MS: yes. Mult Scler. 2013;19:1257-8.

13. Mahad DH, Trapp BD, Lassmann H. Pathological mechanisms in progressive multiple sclerosis. Lancet Neurol. 2015;14:183-93.

14. Bartel DP. MicroRNAs: genomics, biogenesis, mechanism, and function. Cell. 2004;116:281-97.

15. Ha M, Kim VN. Regulation of microRNA biogenesis. Nat Rev Mol Cell Biol. 2014;15:509-24.

16. Hammond SM. An overview of microRNAs. Adv Drug Deliv Rev. 2015;87:3-14

17. Cheng AM, Byrom MW, Shelton J, Ford LP. Antisense inhibition of human miRNAs and indications for an involvement of miRNA in cell growth and apoptosis. Nucleic Acids Res. 2005:33:1290-7.

18. Cheng LC, Tavazoie M, Doetsch F. Stem cells: from epigenetics to microRNAs. Neuron. 2005;46:363-7.

19. Montagner S, Deho L, Monticelli S. MicroRNAs in hematopoietic development. BMC Immunol. 2014;15:14.

20. Lewis BP, Burge CB, Bartel DP. Conserved seed pairing, often flanked by adenosines, indicates that thousands of human genes are microRNA targets. Cell. 2005;120:15-20.

21. Calin GA, Sevignani C, Dumitru CD, Hyslop T, Noch E, Yendamuri S, Shimizu M, Rattan S, Bullrich F, Negrini M, Croce CM. Human microRNA genes are frequently located at fragile sites and genomic regions involved in cancers. Proc Natl Acad Sci U S A. 2004;101:2999-3004.

22. $M a L, B a j i c ~ V B$, Zhang Z. On the classification of long non-coding RNAs. RNA Biol. 2013;10:925-33.

23. Beermann J, Piccoli MT, Viereck J, Thum T. Non-coding RNAs in development and disease: background, mechanisms, and therapeutic approaches. Physiol Rev. 2016;96:1297-325.

24. Hansen TB, Jensen TI, Clausen BH, Bramsen JB, Finsen B, Damgaard CK, Kjems J. Natural RNA circles function as efficient microRNA sponges. Nature. 2013;495:384-8

25. Memczak S, Jens M, Elefsinioti A, Torti F, Krueger J, Rybak A, Maier L, Mackowiak SD, Gregersen LH, Munschauer M, et al. Circular RNAs are a large class of animal RNAs with regulatory potency. Nature. 2013:495:333-8.

26. Salzman J, Gawad C, Wang PL, Lacayo N, Brown PO. Circular RNAs are the predominant transcript isoform from hundreds of human genes in diverse cell types. PLoS One. 2012;7:e30733.

27. Ponting $\mathrm{CP}$, Oliver PL, Reik W. Evolution and functions of long noncoding RNAs. Cell. 2009:136:629-41.

28. Kapranov P, Cheng J, Dike S, Nix DA, Duttagupta R, Willingham AT, Stadler PF, Hertel J, Hackermuller J, Hofacker IL, et al. RNA maps reveal new RNA classes and a possible function for pervasive transcription. Science. 2007; 316:1484-8.

29. Amaral PP, Mattick JS. Noncoding RNA in development. Mamm Genome. 2008:19:454-92.

30. Clemson CM, McNeil JA, Willard HF, Lawrence JB. XIST RNA paints the inactive $X$ chromosome at interphase: evidence for a novel RNA involved in nuclear/chromosome structure. J Cell Biol. 1996;132:259-75.

31. Zhao J, Sun BK, Erwin JA, Song JJ, Lee JT. Polycomb proteins targeted by a short repeat RNA to the mouse X chromosome. Science. 2008;322:750-6.

32. Monnier P, Martinet C, Pontis J, Stancheva I, Ait-Si-Ali S, Dandolo L. H19 IncRNA controls gene expression of the imprinted gene network by recruiting MBD1. Proc Natl Acad Sci U S A. 2013;110:20693-8.

33. Gupta RA, Shah N, Wang KC, Kim J, Horlings HM, Wong DJ, Tsai MC, Hung T, Argani P, Rinn JL, et al. Long non-coding RNA HOTAIR reprograms chromatin state to promote cancer metastasis. Nature. 2010;464:1071-6.

34. Hajjari M, Salavaty AHOTAIR. An oncogenic long non-coding RNA in different cancers. Cancer Biol Med. 2015:12:1-9.

35. Wilusz JE, Freier SM, Spector DL. $3^{\prime}$ end processing of a long nuclear-retained noncoding RNA yields a tRNA-like cytoplasmic RNA. Cell. 2008;135:919-32.

36. Chen LL, Carmichael GG. Decoding the function of nuclear long noncoding RNAs. Curr Opin Cell Biol. 2010;22:357-64.

37. Mercer TR, Dinger ME, Mattick JS. Long non-coding RNAs: insights into functions. Nat Rev Genet. 2009;10:155-9.

38. Hung T, Chang HY. Long noncoding RNA in genome regulation: prospects and mechanisms. RNA Biol. 2010:7:582-5.

39. Xiong XD, Ren X, Cai MY, Yang JW, Liu X, Yang JM. Long non-coding RNAs: an emerging powerhouse in the battle between life and death of tumor cells. Drug Resist Updat. 2016;26:28-42. 
40. Sigdel KR, Cheng A, Wang Y, Duan L, Zhang Y. The emerging functions of long noncoding RNA in immune cells: autoimmune diseases. J Immunol Res. 2015;2015:848790.

41. Wu GC, Pan HF, Leng RX, Wang DG, Li XP, Li XM, Ye DQ. Emerging role of long noncoding RNAs in autoimmune diseases. Autoimmun Rev. 2015;14:798-805.

42. Otaegui D, Baranzini SE, Armananzas R, Calvo B, Munoz-Culla M, Khankhanian P, Inza I, Lozano JA, Castillo-Trivino T, Asensio A, et al. Differential micro RNA expression in PBMC from multiple sclerosis patients. PLoS One. 2009;4:e6309.

43. Du C, Liu C, Kang J, Zhao G, Ye Z, Huang S, Li Z, Wu Z, Pei G. MicroRNA miR-326 regulates $\mathrm{TH}-17$ differentiation and is associated with the pathogenesis of multiple sclerosis. Nat Immunol. 2009;10:1252-9.

44. Keller A, Leidinger P, Lange J, Borries A, Schroers H, Scheffler M, Lenhof HP, Ruprecht K, Meese E. Multiple sclerosis: microRNA expression profiles accurately differentiate patients with relapsing-remitting disease from healthy controls. PLoS One. 2009;4:e7440.

45. Lindberg RL, Hoffmann F, Mehling M, Kuhle J, Kappos L. Altered expression of miR-17-5p in CD4+ lymphocytes of relapsing-remitting multiple sclerosis patients. Eur J Immunol. 2010;40:888-98.

46. De Santis G, Ferracin M, Biondani A, Caniatti L, Rosaria Tola M, Castellazzi M, Zagatti B, Battistini L, Borsellino G, Fainardi E, et al. Altered miRNA expression in T regulatory cells in course of multiple sclerosis. J Neuroimmunol. 2010;226:165-71.

47. Ehya F, Abdul Tehrani H, Garshasbi M, Nabavi SM. Identification of miR-24 and miR-137 as novel candidate multiple sclerosis miRNA biomarkers using multi-staged data analysis protocol. Mol Biol Res Commun. 2017;6:127-40.

48. Fenoglio C, Ridolfi E, Cantoni C, De Riz M, Bonsi R, Serpente M, Villa C, Pietroboni AM, Naismith RT, Alvarez E, et al. Decreased circulating miRNA levels in patients with primary progressive multiple sclerosis. Mult Scler. 2013;19:1938-42.

49. Gandhi R, Healy B, Gholipour T, Egorova S, Musallam A, Hussain MS, Nejad $P$, Patel B, Hei H, Khoury S, et al. Circulating microRNAs as biomarkers for disease staging in multiple sclerosis. Ann Neurol. 2013;73:729-40.

50. Kacperska MJ, Jastrzebski K, Tomasik B, Walenczak J, Konarska-Krol M, Glabinski A. Selected extracellular microRNA as potential biomarkers of multiple sclerosis activity--preliminary study. J Mol Neurosci. 2015;56:154-63.

51. Niwald M, Migdalska-Sek M, Brzezianska-Lasota E, Miller E. Evaluation of selected microRNAs expression in remission phase of multiple sclerosis and their potential link to cognition, depression, and disability. J Mol Neurosci. 2017;63:275-82

52. Siegel SR, Mackenzie J, Chaplin G, Jablonski NG, Griffiths L. Circulating microRNAs involved in multiple sclerosis. Mol Biol Rep. 2012;39:6219-25.

53. Ebrahimkhani S, Vafaee F, Young PE, Hur SSJ, Hawke S, Devenney E, Beadnall H, Barnett MH, Suter CM, Buckland ME. Exosomal microRNA signatures in multiple sclerosis reflect disease status. Sci Rep. 2017;7:14293.

54. Haghikia A, Haghikia A, Hellwig K, Baraniskin A, Holzmann A, Decard BF, Thum T, Gold R. Regulated microRNAs in the CSF of patients with multiple sclerosis: a case-control study. Neurology. 2012;79:2166-70.

55. Bruinsma IB, van Dijk M, Bridel C, van de Lisdonk T, Haverkort SQ, Runia TF Steinman L, Hintzen RQ, Killestein J, Verbeek MM, et al. Regulator of oligodendrocyte maturation, miR-219, a potential biomarker for MS. J Neuroinflammation. 2017;14:235.

56. Bergman $\mathrm{P}$, Piket $\mathrm{E}$, Khademi $\mathrm{M}$, James $\mathrm{T}$, Brundin $\mathrm{L}$, Olsson $\mathrm{T}$, Piehl F, Jagodic M. Circulating miR-150 in CSF is a novel candidate biomarker for multiple sclerosis. Neurol Neuroimmunol Neuroinflamm. 2016;3:e219.

57. Hunt D, Giovannoni G. Natalizumab-associated progressive multifocal leucoencephalopathy: a practical approach to risk profiling and monitoring. Pract Neurol. 2012;12:25-35.

58. Basnyat P, Virtanen E, Elovaara I, Hagman S, Auvinen E. JCPyV microRNA in plasma inversely correlates with JCPyV seropositivity among long-term natalizumab-treated relapsing-remitting multiple sclerosis patients. J NeuroOncol. 2017:23:734-41.

59. Hu R, Huffaker TB, Kagele DA, Runtsch MC, Bake E, Chaudhuri AA, Round IL, O'Connell RM. MicroRNA-155 confers encephalogenic potential to Th17 cells by promoting effector gene expression. J Immunol. 2013;190:5972-80.

60. O'Connell RM, Kahn D, Gibson WS, Round JL, Scholz RL, Chaudhuri AA, Kahn ME, Rao DS, Baltimore D. MicroRNA-155 promotes autoimmune inflammation by enhancing inflammatory T cell development. Immunity. 2010;33:607-19.

61. Zhang J, Cheng Y, Cui W, Li M, Li B, Guo L. MicroRNA-155 modulates Th1 and Th17 cell differentiation and is associated with multiple sclerosis and experimental autoimmune encephalomyelitis. J Neuroimmunol. 2014;266: 56-63.

62. Escobar TM, Kanellopoulou C, Kugler DG, Kilaru G, Nguyen CK, Nagarajan V, Bhairavabhotla RK, Northrup D, Zahr R, Burr P, et al. miR-155 activates cytokine gene expression in Th17 cells by regulating the DNA-binding protein Jarid2 to relieve polycomb-mediated repression. Immunity. 2014;40: 865-79.

63. Liu Q, Gao Q, Zhang Y, Li Z, Mei X. MicroRNA-590 promotes pathogenic Th17 cell differentiation through targeting Tob1 and is associated with multiple sclerosis. Biochem Biophys Res Commun. 2017:493:901-8.

64. Wu R, He Q, Chen H, Xu M, Zhao N, Xiao Y, Tu QQ, Zhang W, Bi X. MicroRNA-448 promotes multiple sclerosis development through induction of Th17 response through targeting protein tyrosine phosphatase nonreceptor type 2 (PTPN2). Biochem Biophys Res Commun. 2017:486:759-66.

65. Guan H, Fan D, Mrelashvili D, Hao H, Singh NP, Singh UP, Nagarkatti PS, Nagarkatti M. MicroRNA let-7e is associated with the pathogenesis of experimental autoimmune encephalomyelitis. Eur J Immunol. 2013:43:104-14.

66. Ahmadian-Elmi M, Bidmeshki Pour A, Naghavian R, Ghaedi K, Tanhaei S, Izadi T, Nasr-Esfahani MH. miR-27a and miR-214 exert opposite regulatory roles in Th17 differentiation via mediating different signaling pathways in peripheral blood CD4+ T lymphocytes of patients with relapsing-remitting multiple sclerosis. Immunogenetics. 2016;68:43-54.

67. Liu R, Ma X, Chen L, Yang Y, Zeng Y, Gao J, Jiang W, Zhang F, Li D, Han B, et al. MicroRNA-15b suppresses Th17 differentiation and is associated with pathogenesis of multiple sclerosis by targeting O-GlcNAc transferase. J Immunol. 2017;198:2626-39.

68. Hanieh $\mathrm{H}$, Alzahrani A. MicroRNA-132 suppresses autoimmune encephalomyelitis by inducing cholinergic anti-inflammation: a new Ahrbased exploration. Eur J Immunol. 2013;43:2771-82.

69. Guan H, Singh UP, Rao R, Mrelashvili D, Sen S, Hao H, Zumbrun EE, Singh NP, Nagarkatti PS, Nagarkatti M. Inverse correlation of expression of microRNA-140-5p with progression of multiple sclerosis and differentiation of encephalitogenic T helper type 1 cells. Immunology. 2016;147:488-98.

70. Guerau-de-Arellano M, Smith KM, Godlewski J, Liu Y, Winger R, Lawler SE, Whitacre CC, Racke MK, Lovett-Racke AE. Micro-RNA dysregulation in multiple sclerosis favours pro-inflammatory T-cell-mediated autoimmunity. Brain. 2011;134:3578-89.

71. Aung LL, Mouradian MM, Dhib-Jalbut S, Balashov KE. MMP-9 expression is increased in B lymphocytes during multiple sclerosis exacerbation and is regulated by microRNA-320a. J Neuroimmunol. 2015;278:185-9.

72. Chandler S, Coates R, Gearing A, Lury J, Wells G, Bone E. Matrix metalloproteinases degrade myelin basic protein. Neurosci Lett. 1995; 201:223-6.

73. Asahi M, Wang X, Mori T, Sumii T, Jung JC, Moskowitz MA, Fini ME, Lo EH. Effects of matrix metalloproteinase-9 gene knock-out on the proteolysis of blood-brain barrier and white matter components after cerebral ischemia. J Neurosci. 2001:21:7724-32.

74. Sievers C, Meira M, Hoffmann F, Fontoura P, Kappos L, Lindberg RL. Altered microRNA expression in B lymphocytes in multiple sclerosis: towards a better understanding of treatment effects. Clin Immunol. 2012;144:70-9.

75. Miyazaki Y, Li R, Rezk A, Misirliyan H, Moore C, Faroogi N, Solis M, Goiry LG, de Faria Junior O, Dang VD, et al. A novel microRNA-132-sirtuin-1 axis underlies aberrant B-cell cytokine regulation in patients with relapsingremitting multiple sclerosis [corrected]. PLoS One. 2014;9:e105421.

76. Huang Q, Xiao B, Ma X, Qu M, Li Y, Nagarkatti P, Nagarkatti M, Zhou J. MicroRNAs associated with the pathogenesis of multiple sclerosis. J Neuroimmunol. 2016:295-296:148-61.

77. Moore CS, Rao VT, Durafourt BA, Bedell BJ, Ludwin SK, Bar-Or A, Antel JP. miR-155 as a multiple sclerosis-relevant regulator of myeloid cell polarization. Ann Neurol. 2013;74:709-20.

78. Ponomarev ED, Veremeyko T, Barteneva N, Krichevsky AM, Weiner HL. MicroRNA-124 promotes microglia quiescence and suppresses EAE by deactivating macrophages via the C/EBP-alpha-PU.1 pathway. Nat Med. 2011;17:64-70.

79. Luo D, Fu J. Identifying characteristic miRNAs-genes and risk pathways of multiple sclerosis based on bioinformatics analysis. Oncotarget. 2018;9: 5287-300.

80. Junker A, Krumbholz M, Eisele S, Mohan H, Augstein F, Bittner R, Lassmann $H$, Wekerle $H$, Hohlfeld R, Meinl E. MicroRNA profiling of multiple sclerosis lesions identifies modulators of the regulatory protein CD47. Brain. 2009: 132:3342-52. 
81. Dugas JC, Cuellar TL, Scholze A, Ason B, Ibrahim A, Emery B, Zamanian JL, Foo LC, McManus MT, Barres BA. Dicer1 and miR-219 are required for normal oligodendrocyte differentiation and myelination. Neuron. 2010;65: 597-611.

82. Lin ST, Fu YH. miR-23 regulation of lamin B1 is crucial for oligodendrocyte development and myelination. Dis Model Mech. 2009;2:178-88.

83. Santoro M, Nociti V, Lucchini M, De Fino C, Losavio FA, Mirabella M. Expression profile of long non-coding RNAs in serum of patients with multiple sclerosis. J Mol Neurosci. 2016;59:18-23.

84. Zhang F, Gao C, Ma XF, Peng XL, Zhang RX, Kong DX, Simard AR, Hao JW. Expression profile of long noncoding RNAs in peripheral blood mononuclear cells from multiple sclerosis patients. CNS Neurosci Ther. 2016; 22:298-305.

85. Eftekharian MM, Ghafouri-Fard S, Soudyab M, Omrani MD, Rahimi M, Sayad A, Komaki A, Mazdeh M, Taheri M. Expression analysis of long non-coding RNAs in the blood of multiple sclerosis patients. J Mol Neurosci. 2017;63: 333-41.

86. Miron VE, Boyd A, Zhao JW, Yuen TJ, Ruckh JM, Shadrach JL, van Wijngaarden P, Wagers AJ, Williams A, Franklin RJM, Ffrench-Constant C. M2 microglia and macrophages drive oligodendrocyte differentiation during CNS remyelination. Nat Neurosci. 2013;16:1211-8.

87. Sun D, Yu Z, Fang X, Liu M, Pu Y, Shao Q, Wang D, Zhao X, Huang A, Xiang $Z$, et al. LncRNA GAS5 inhibits microglial M2 polarization and exacerbates demyelination. EMBO Rep. 2017;18:1801-16.

88. Cao Y, Goods BA, Raddassi K, Nepom GT, Kwok WW, Love JC, Hafler DA. Functional inflammatory profiles distinguish myelin-reactive $T$ cells from patients with multiple sclerosis. Sci Transl Med. 2015;7:287ra274.

89. Hiltensperger M, Korn T. The interleukin (IL)-23/T helper (Th) 17 axis in experimental autoimmune encephalomyelitis and multiple sclerosis. Cold Spring Harb Perspect Med. 2018;8:a029637.

90. Aharoni R, Teitelbaum D, Leitner O, Meshorer A, Sela M, Arnon R. Specific Th2 cells accumulate in the central nervous system of mice protected against experimental autoimmune encephalomyelitis by copolymer 1. Proc Natl Acad Sci U S A. 2000;97:11472-7.

91. Zhang F, Liu G, Wei C, Gao C, Hao J. Linc-MAF-4 regulates Th1/Th2 differentiation and is associated with the pathogenesis of multiple sclerosis by targeting MAF. FASEB J. 2017;31:519-25.

92. Han B, Chao J, Yao H, Circular RNA. Its mechanisms in disease: from the bench to the clinic. Pharmacol Ther. 2018;187:31-44.

93. Cardamone G, Paraboschi EM, Rimoldi V, Duga S, Solda G, Asselta R. The characterization of GSDMB splicing and backsplicing profiles identifies novel isoforms and a circular RNA that are dysregulated in multiple sclerosis. Int J Mol Sci. 2017;18:E576.

94. Iparraguirre L, Munoz-Culla M, Prada-Luengo I, Castillo-Trivino T, Olascoaga J, Otaegui D. Circular RNA profiling reveals that circular RNAs from ANXA2 can be used as new biomarkers for multiple sclerosis. Hum Mol Genet. 2017;26:3564-72.

95. Fenoglio C, Cantoni C, De Riz M, Ridolfi E, Cortini F, Serpente M, Villa C, Comi C, Monaco F, Mellesi L, et al. Expression and genetic analysis of miRNAs involved in CD4+ cell activation in patients with multiple sclerosis. Neurosci Lett. 2011;504:9-12.

96. Dutta R, Chomyk AM, Chang A, Ribaudo MV, Deckard SA, Doud MK, Edberg DD, Bai B, Li M, Baranzini SE, et al. Hippocampal demyelination and memory dysfunction are associated with increased levels of the neuronal microRNA miR-124 and reduced AMPA receptors. Ann Neurol. 2013;73:637-45.

97. Colombo T, Farina L, Macino G, Paci P. PVT1: a rising star among oncogenic long noncoding RNAs. Biomed Res Int. 2015;2015:304208

98. Gnanaprakasam JN, Wang R. MYC in regulating immunity: metabolism and beyond. Genes (Basel). 2017;8:88.

Ready to submit your research? Choose BMC and benefit from:
- fast, convenient online submission
- thorough peer review by experienced researchers in your field
- rapid publication on acceptance
- support for research data, including large and complex data types
- gold Open Access which fosters wider collaboration and increased citations
- maximum visibility for your research: over 100M website views per year
At BMC, research is always in progress.
Learn more biomedcentral.com/submissions

